\title{
FAR-INFRARED EMISSION CHARACTERISTICS AND WEAR COMFORT PROPERTY OF ZrC-IMBEDDED HEAT STORAGE KNITTED FABRICS FOR EMOTIONAL GARMENTS
}

\author{
Hyun Ah Kim¹, Seung Jin Kim² \\ ${ }^{1}$ Korea Research Institute for Fashion Industry, Daegu, Korea \\ ${ }^{2}$ Dept. of Textile Eng. and Technology, Yeungnam Univ, Gyeongsan, Korea
}

\begin{abstract}
:
This study examined the far-infrared emission characteristics and wear comfort properties of ZrC-imbedded heat storage knitted fabrics. For this purpose, ZrC-imbedded, heat storage PET (polyethylene terephthalate) was spun from high-viscosity PET with imbedded ZrC powder on the core part and low-viscosity PET on the sheath part using a conjugated spinning method. ZrC-imbedded PET knitted fabric was also prepared and its physical properties were measured and compared with those of regular PET knitted fabric. In addition, ingredient analysis and the far-infrared emission characteristics of the ZrC-imbedded knitted fabrics were analyzed by energy dispersive $X$-ray spectroscopy and Fourier transform infrared spectroscopy. The thermal properties, moisture absorption, and drying properties of the ZrC-imbedded PET knitted fabric were measured and compared with those of the regular PET knitted fabric. The mechanical properties using the FAST (fabric assurance by simple testing) system and the dye affinity of the $\mathrm{ZrC}$-imbedded knitted fabric were also measured and compared with those of regular PET knitted fabric.
\end{abstract}

\section{Keywords:}

far-infrared, ZrC-imbedded knitted fabric, wicking property, wear comfort, warmth keepability rate.

\section{Introduction}

Warmth keepability of textile materials are divided into two methods for providing the functions related to the heat keeping property, passive and positive methods. One of the positive methods is the ZrC-imbedded yarn manufacturing method, which is a heat storage method by far-infrared emission from the ceramics in the yarn. Solar- $\alpha$ commercialized by Unitica [12] in Japan is a heat storage fiber imbedded with $\mathrm{ZrC}$ in the core part of the nylon filament. Kuraray [9], Mitsubishirayon [10], and Kanebo [8] in Japan developed heat storage filaments using $\mathrm{ZrC}$ applicable to bedding textiles. Infrared radiation is a type of thermal ray, and its wavelength is divided into four regions. The infrared region at wavelengths from 6 to $14 \mu \mathrm{m}$ is defined as the far-infrared region and its emissivity is about $91 \%$. According to the early study of Beak et al. [2], the thermal effects of far-infrared rays was investigated using far-infrared-duplicated materials made from yellow clay by Fourier transform infrared analysis. Lin et al. [15] examined the heat keepability by the far-infrared emission characteristics using nonwoven fabrics treated with the carbonized powder of charcoal fibers. On the other hand, $\mathrm{ZrC}$, which is a kind of ceramic material with optical reflectance of $76 \%$, heat capacity of $0.088 \mathrm{cal} / \mathrm{g}^{\circ} \mathrm{C}$, and thermal conductivity of $12 \mathrm{~W} / \mathrm{m}^{\circ} \mathrm{C}$, imbedded in the yarn emits far-infrared radiation [14]. The heat storage characteristics of the ZrC-imbedded fabrics, which are known as Thermotron by Unitica (Japan) [12], Megatron by Toray (Japan) [11], and Reothermo by Asahnkasei (Japan) [7], were achieved by transforming to thermal energy after absorbing near-infrared light from sun light. Another function of $\mathrm{ZrC}$ imbedded in the yarn and fabric is that $\mathrm{ZrC}$ absorbs the heat emitted from the human body and/or reflects far-infrared radiation, which prevents the heat from flowing out [16]. On the other hand, despite the many Japanese fiber companies providing some technical data as a commercial base, the farinfrared emission characteristics and wear comfort properties of the ceramic-imbedded warm-up suit materials were less well known because of the confidentiality and patent problems. The basic studies related to the heat storage filament are as follows. In earlier research, Furuta et al. [5] developed a heat storage fabric using 2 wt.\% ZrC-imbedded PET and confirmed the increase in moisture permeability of these ZrC-imbedded PET fabrics. Recently, Bahng et al. [1] developed heat-generating fibers by imbedding ceramic powder in the PET. They reported the superior moisture absorption and fast dry characteristics of this ceramic-imbedded fabric, which were attributed to the rapid evaporation of perspiration from the human body by the heat developed from the ceramic-imbedded filament. Kim et al. [13] examined the far-infrared emission characteristics of germanium-imbedded fabrics and found that the emission power of germanium-imbedded fabric was $3.53 \times 10^{2} \mathrm{~W} / \mathrm{m}^{2}$ over the 5-20 $\mu \mathrm{m}$ wavelength range and the emissivity was 0.874 . Shim et al. [17] developed a warm-up suit with good thermal performance and investigated the heat-insulating water-vaporpermeable property of the warm-up suit by applying ceramic powders to a hydrophilic polyurethane film. Many studies $[19,20]$ have examined the heat keeping property of nylon fabrics by a coating with ceramic-imbedded resin. On the other hand, there has been little research related to the far-infrared emission characteristics and wear comfort property of ceramicimbedded fabrics including the heat generation and storage characteristics with moisture absorption and drying properties. Therefore, this study examined the far-infrared emission characteristics and wear comfort property of $\mathrm{ZrC}$-imbedded 
heat storage knitted fabrics. For this purpose, ZrC-imbedded heat storage PET was spun with high-viscosity PET imbedded with $\mathrm{ZrC}$ powder on the core part and low-viscosity PET on the sheath part by conjugated spinning. ZrC-imbedded PET knitted fabric was also prepared and its thermal, wicking, and drying properties were measured and compared with those of regular PET knitted fabrics. In addition, the composition and the farinfrared emission characteristics of $\mathrm{ZrC}$-imbedded PET were analyzed by energy dispersive X-ray spectroscopy (EDS) and Fourier transform infrared (FT-IR) spectroscopy. In addition, the mechanical properties were also measured by the FAST system and the dye affinity was measured and compared with those of regular PET knitted fabrics.

\section{Experimental}

\subsection{Specimens}

1) Yarn preparation

ZrC-imbedded PET was spun by a conjugated spinning method on pilot spinning machine in Huvis in Korea. POY (Partially Oriented Yarn) $125^{\mathrm{d}} / 36^{\mathrm{f}}$ with low-viscosity PET on the sheath part and ZrC mixed high-viscosity PET on the core part was spun on a bicomponent spinning machine, which is shown in Fig. 1. The spinning temperature was $285^{\circ} \mathrm{C}$, and the spinning speed was 3,000 $\mathrm{m} / \mathrm{min}$. The ZrC content was $1.2 \mathrm{wt} . \%$, which was mixed with high-viscosity PET at the core position in the extruder as a Master batch chip. This POY was texturized with the following texturing conditions: draw ratio, 1.65; heat temperature, $190^{\circ} \mathrm{C}$; and velocity ratio (belt speed/feed speed), 1.75 on a Murata $33 \mathrm{H}$ (Japan) texturing machine. Figure 2 presents a schematic diagram of the Murata $33 \mathrm{H}$ texturing machine. The draw ratio was decided by the surface velocity ratio between 1 st and 2 nd delivery rollers. The velocity ratio was set by the ratio between the belt and yarn feed speeds on the nip twister in Fig. 2. To compare with this $\mathrm{ZrC}$-imbedded yarn specimen, two kinds of nanoceramic-treated PET DTY (Ceraheat, Sahara) were prepared and regular PET was selected as the control yarn. Table 1 presents details of these yarn specimens.

\section{2) Knitted fabric preparation}

Table 1 lists the four kinds of knitted fabrics made on a circular knitting machine (Gumyong ${ }^{\circledR}$, Korea) using the yarn specimens. The specification of the knitting machine was 30 inches in diameter and 28 gauge. Two patterns (corduroy and crepe) were knitted with $18 \mathrm{rpm}$ and 2,460 needles. The patterns of the knitted fabrics were decided as corduroy and crepe, which were recommended by the knitted fabric designer and were most relevant to the commercial market for the $\mathrm{ZrC}$ imbedded PET filament. In corduroy, the surface filament was PET DTY $100^{\mathrm{d}} / 48^{\mathrm{f}}$ and the reverse filament was four kinds of $75^{\mathrm{d}} / 36^{\mathrm{f}}$ yarns, as shown in Table 1 . In crepe, the surface filament was $150^{d} / 144^{f}$ PET DTY and the reverse filament was

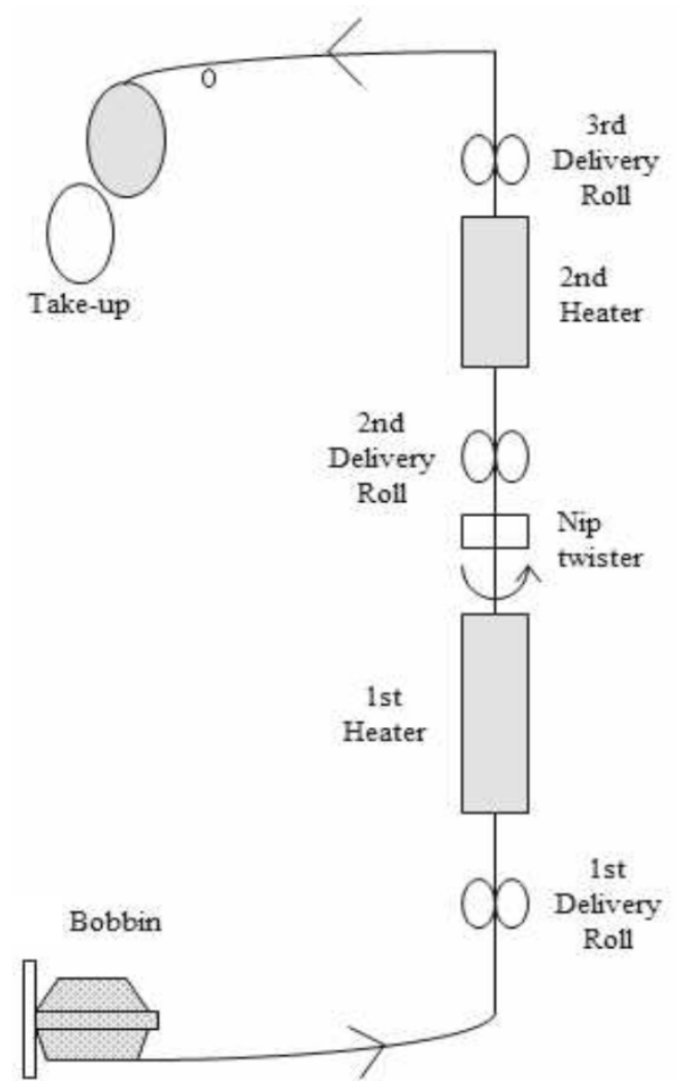

Figure 2. Illustration of Murata DTY (Murata 33H) machine.

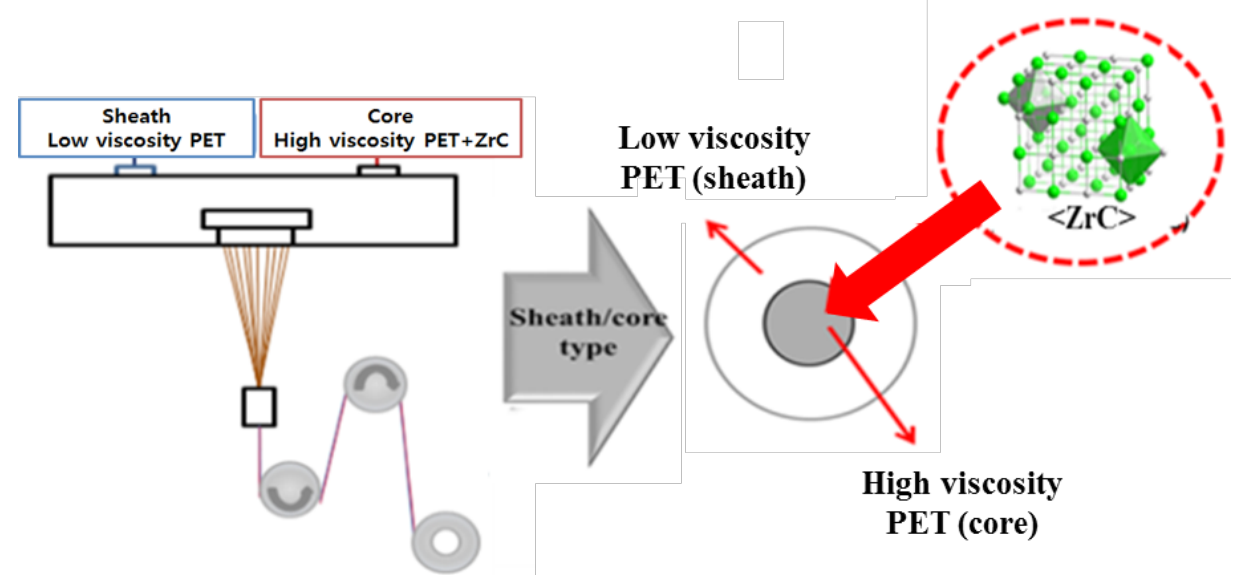

Figure 1. Schematic diagram of the bicomponent spinning of ZrC-imbedded filament. 
four kinds of $75^{\mathrm{d}} / 36^{\mathrm{f}}$ yarns, as shown in Table 1 . Table 2 lists the characteristics of the knitted fabric specimens. The loop length was measured by the total loop length divided by the loop numbers of the fifty loops, and the weight of the knitted fabric specimen was measured by three readings. Table 3 lists the pattern structures of the knitted fabric specimens.

\subsection{Dyeing Conditions of the Knitted Fabric Specimens}

Pretreatment of the four kinds of knitted fabric specimens was carried out using $2 \mathrm{~g} / \mathrm{Na}_{2} \mathrm{CO}_{3}$ and $1 \mathrm{~g} / \mathrm{l}$ of a scouring agent, Sunmorl SS-30, at a treatment temperature of $80^{\circ} \mathrm{C}$ for 20 $\mathrm{min}$ in a scouring bath. The dyeing characteristics of the $\mathrm{ZrC}$ imbedded knitted fabrics were examined at different dyeing temperatures $\left(110,120\right.$, and $\left.130^{\circ} \mathrm{C}\right)$ and dyeing times $(30$, 40 and $60 \mathrm{~min}$.). Table 4 lists the dyeing conditions of the $\mathrm{ZrC}$ imbedded knitted fabric.

\subsection{Measurement of Physical Property}

1) Ingredient analysis of the $\mathrm{ZrC}$-imbedded yarn

Ingredient analysis of the three kinds of ceramic-imbedded yarn specimens was performed by EDS (JEOL LV8500, Japan).

2) Characteristics of far-infrared emission

The far-infrared emission characteristics of the ZrC-imbedded yarn was measured using an FT-IR spectrometer (Midac M2400-C, USA). The emissivity and emissive power were calculated using the Plank formula. [6][19] The emissive power and emissivity were measured at $40^{\circ} \mathrm{C}$, resolution of $8 \mathrm{~cm}^{-1}$, and wavelength range of 5-20 $\mu \mathrm{m}$.
3 ) Scanning electron microscopy (SEM) and optical microscopy measurements.

Cross sections of the yarns and fabrics were measured by SEM (S-4300, Hitachi Co. Japan.) and optical microscopy (i Camscope 305A, Korea)

4) Thermal conductivity and warmth keepability rate

The thermal conductivity (K) was measured using a KES-F7 (Thermo labo II, Kato Tech. Co. Ltd, Japan) and calculated using equation (1)

$$
K=\frac{W \cdot D}{A \cdot \Delta T}
$$

where $\mathrm{K}$ is the thermal conductivity $\left(\mathrm{W} / \mathrm{m}^{\circ} \mathrm{C}\right)$

$\mathrm{W}$ is the heat loss $\left(\mathrm{W} / \mathrm{cm}^{2}\right)$

$D$ is the specimen thickness $(\mathrm{cm})$

A is the area of specimen $\left(\mathrm{cm}^{2}\right)$

$\mathrm{T}$ is the temperature $\left({ }^{\circ} \mathrm{C}\right)$

The warmth keepability rate (I) and maximum heat flux $\left(Q_{\text {max }}\right)$ at the transient state were also measured using KES-F7 at 22 $\pm 1^{\circ} \mathrm{C}$ and $70 \pm 5 \%$, R.H., respectively. The warmth keepability rate was calculated using equation (2).[4]

$$
I=\left(1-\frac{b}{a}\right) \times 100
$$

where $a$ is the heat emanated from the test plate (W), $b$ is the heat emanated from the test specimen mounted $(W)$

\begin{tabular}{|c|c|c|c|c|c|c|c|}
\hline \multirow[b]{2}{*}{ Specimens } & \multirow[b]{2}{*}{ Specification } & \multirow{2}{*}{$\begin{array}{l}\text { Measured } \\
\text { yarn linear } \\
\text { density(d) }\end{array}$} & \multicolumn{4}{|c|}{ Physical properties } & \multirow[b]{2}{*}{ Characteristics } \\
\hline & & & $\begin{array}{c}\text { Tenacity } \\
\left(g_{f} / d\right)\end{array}$ & $\begin{array}{l}\text { Breaking } \\
\text { strain (\%) }\end{array}$ & $\begin{array}{c}\text { Initial } \\
\text { modulus } \\
\left(g_{f} / d\right)\end{array}$ & $\begin{array}{c}\text { Thermal } \\
\text { shrinkage } \\
(\%)\end{array}$ & \\
\hline H-PET & DTY $75 d / 36 f$ & 73.6 & 4.368 & 48.9 & 10.2 & 46.03 & $\mathrm{ZrC}$ imbedded \\
\hline S-PET & DTY $75 d / 72 f$ & 74.2 & 4.661 & 16.7 & 30.9 & 17.46 & Nano powder \\
\hline C-PET & DTY 75d/72f & 74.5 & 4.056 & 6.0 & 39.7 & 13.54 & Ceramic powder \\
\hline R-PET & DTY 75d/72f & 73.8 & 4.721 & 18.6 & 28.6 & 12.71 & Regular PET \\
\hline
\end{tabular}

Table 1. Characteristics of the yarn specimens.

\begin{tabular}{|c|c|c|c|c|c|c|}
\hline \multirow{3}{*}{ Specimens } & \multicolumn{3}{|c|}{ Corduroy } & \multicolumn{3}{|c|}{ Crepe } \\
\hline & \multicolumn{2}{|c|}{ Loop length(mm) } & \multirow{2}{*}{$\begin{array}{l}\text { Weight } \\
\left(\mathrm{g} / \mathrm{m}^{2}\right)\end{array}$} & \multicolumn{2}{|c|}{ Loop length(mm) } & \multirow{2}{*}{$\begin{array}{l}\text { Weight } \\
\left(\mathrm{g} / \mathrm{m}^{2}\right)\end{array}$} \\
\hline & cylinder & dial & & cylinder & dial & \\
\hline $\mathrm{H}$ & 10.9 & 12.9 & 263.18 & 12.1 & 20.8 & 214.15 \\
\hline$S$ & 11.2 & 13.1 & 267.13 & 11.6 & 20.1 & 207.26 \\
\hline C & 11.4 & 13.4 & 269.39 & 11.9 & 20.4 & 209.52 \\
\hline $\mathrm{R}$ & 10.6 & 12.7 & 250.55 & 11.8 & 20.3 & 208.35 \\
\hline
\end{tabular}

Table 2. Characteristics of the knitted fabric specimens. 
Table 3. Pattern structure of the knitted fabric specimens.

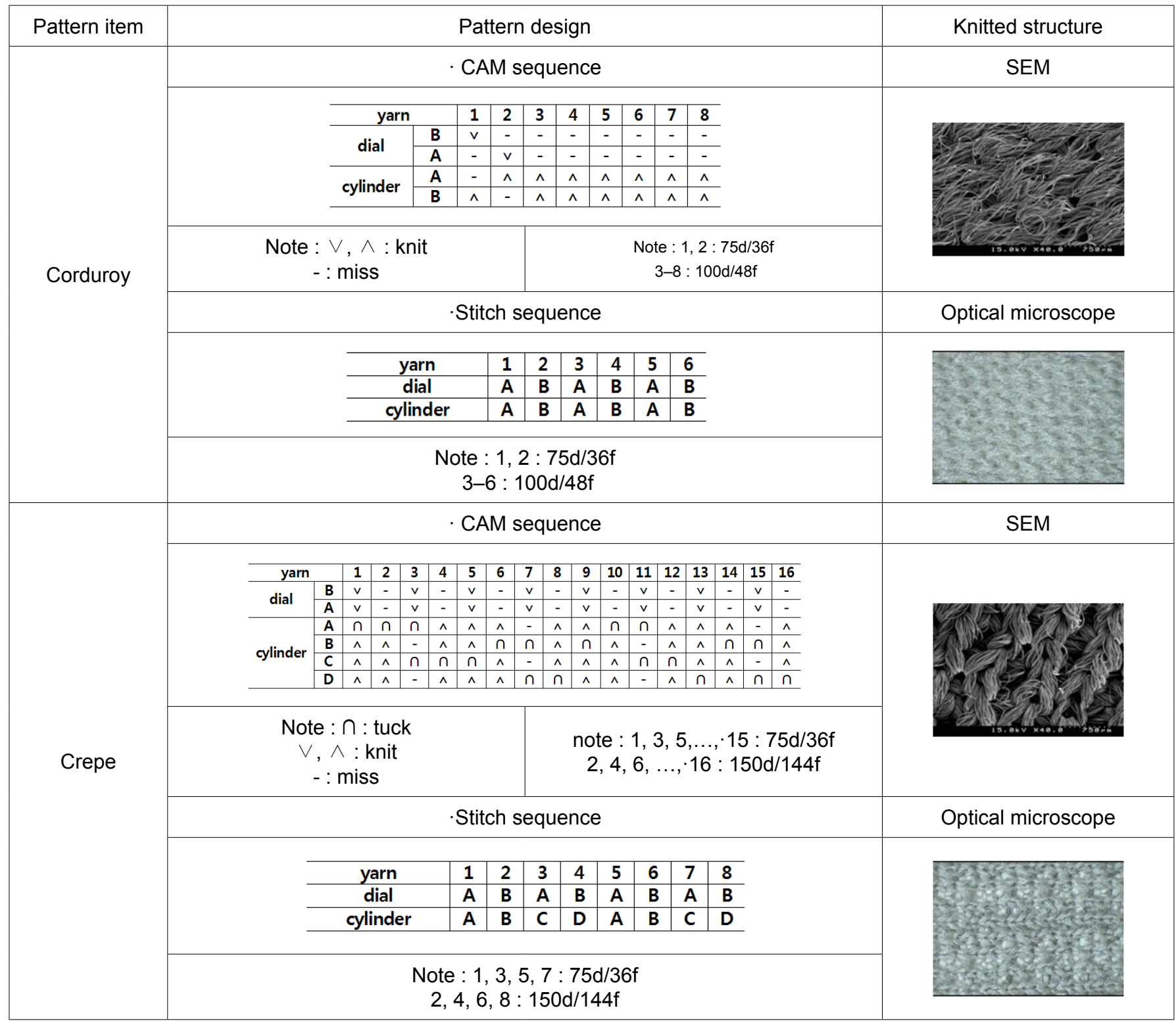

Table 4. Dyeing condition of the ceramic-imbedded knitted fabric.

\begin{tabular}{|c|c|c|c|c|}
\hline $\begin{array}{c}\text { Dyeing } \\
\text { temperature }\left({ }^{\circ} \mathrm{C}\right)\end{array}$ & \multicolumn{3}{|c|}{ Dyeing time(min) } & Fixed condition \\
\hline 110 & 30 & 40 & 60 & \multirow{3}{*}{$\begin{array}{l}\text { Scouring } \\
\text { - Soda ash }\left(\mathrm{Na}_{2} \mathrm{CO}_{3}\right) 2 \mathrm{~g} / \mathrm{ll}, \text { Scouring } \\
\text { agent }(\mathrm{Sunmorl} \mathrm{SS}-30) 1 \mathrm{~g} / \mathrm{l}, 80^{\circ} \mathrm{C} \text {, } \\
20 \mathrm{~min} \\
\text { Dyeing } \\
\text { - Disperse dye (FORON BLUES- } \\
\text { BGL200-Claiant), (C.I.Disperse } \\
\text { Blue78), dispersing agent (RM340) } \\
0.5 \mathrm{~g} / \mathrm{l} \\
\text { Reduction clearing } \\
\text { - NaOH } 2 \mathrm{~g} / \mathrm{l}, \mathrm{Na}_{2} \mathrm{~S}_{2} \mathrm{O}_{4} 1 \mathrm{~g} / \mathrm{l}, 80^{\circ} \mathrm{C}, 20 \\
\text { min }\end{array}$} \\
\hline 120 & 30 & 40 & 60 & \\
\hline 130 & 30 & 40 & 60 & \\
\hline
\end{tabular}




\section{5) Absorption and drying characteristics}

The moisture absorption of the knitted fabric specimens was measured using the Bireck method (KSK0815). The strip specimen $(20 \mathrm{~cm} \times 2.5 \mathrm{~cm})$ was prepared, and one end of the strip was dipped in distilled water $\left(27^{\circ} \mathrm{C} \pm 2^{\circ} \mathrm{C}\right)$. The wicking length $(\mathrm{mm})$ for every $10 \mathrm{~min}$ was assessed for $30 \mathrm{~min}$. The drying rate was assessed using a measuring device (INTEC. Co. Ltd, Japan) according to KSK0815A. The specimen $(40 \mathrm{~cm}$ $\times 40 \mathrm{~cm})$ was dipped in a water bath $\left(27 \pm 2^{\circ} \mathrm{C}\right)$ and taken out from the water bath. The specimen was hung on the measuring device after no water drops were observed on the specimen. The time until natural drying under standard conditions was measured using a sensor and was taken as the drying rate.

6) Mechanical properties of knitted fabric

The mechanical properties of the knitted fabric were measured using a FAST (fabric assurance simple testing) system. The shear rigidity $(\mathrm{G})$ was calculated using EB5, as shown in Eq. (3), which was measured using a FAST-3 measuring device.

$$
G=\left(\frac{123}{E B 5}\right) \times 1 \mathrm{~N} / \mathrm{m}
$$

where $G$ is the shear rigidity $(\mathrm{N} / \mathrm{m})$

EB5 is the bias extension under the $5 \mathrm{gf} / \mathrm{cm}$ width (\%)

The bending rigidity $(\mathrm{B})$ was calculated using $\mathrm{c}$, as shown in Eq. (4), which was measured using a FAST-2 measuring device.

$$
B=W \times c^{3} \times 9.81 \times 10^{6}
$$

where $B$ is the bending rigidity $(\mu \mathrm{N} \cdot \mathrm{m})$

$C$ is the bending length $(\mathrm{mm})$

$W$ is the weight per unit area $\left(g_{f} / m^{2}\right)$

The extensibility and compressibility were measured using the FAST-3 and FAST-1 measuring devices, respectively. The extensibility was measured at a load of $20 \mathrm{~g} / \mathrm{cm}$ width using FAST-3, and the compressibility was calculated as the difference in thickness of a fabric measured at pressure of 2and $100 \mathrm{~g}_{\mathrm{f}} / \mathrm{cm}^{2}$, which is called the surface thickness [3]. In this study, it was assumed that the higher this value, the more compressible is the knitted fabric.

\section{7) Analysis of dye affinity}

The reflectance $(R)$ of the knitted fabric specimens according to the dyeing temperatures and times was measured using a color measuring device (Gretag Macbath, Color-Eye 3100). The dye affinity $(\mathrm{K} / \mathrm{S})$ was calculated from the reflectance, as shown in Eq. (5) [18].

$$
K / S=\frac{(1-R)^{2}}{2 R}
$$

where $\mathrm{R}$ is the reflection rate

$\mathrm{K}$ is the absorption factor

$\mathrm{S}$ is the scattering factor

\section{Results and discussion}

\subsection{Ingredient Analysis of ZrC-Imbedded Yarn}

Figure 3 presents the results of ingredient analysis of the three kinds of ceramic imbedded yarns. As shown in Fig. 3 (a) and (e), H-PET has a Zr ingredient peak and a content of $19.29 \%$. S-PET contained small amounts of $\mathrm{Na}, \mathrm{Cl}$, and $\mathrm{Fe}$, and C-PET also contained small amounts of $\mathrm{Zn}, \mathrm{Al}$, and Ti. However, R-PET only had $\mathrm{Ti}$ and $\mathrm{Si}$, which appears to be a delustre particle imbedded usually in the PET filament. H-PET had much larger amounts of $\mathrm{Zr}$ according to EDS. Figure 4 shows white spots on the yarn cross-section in the SEM image of the $\mathrm{H}$ specimen (Fig. 4(a)), which were assumed to be $\mathrm{ZrC}$. These white spots were not shown in Fig. 4(b) and (c). Inorganic particles imbedded in these yarns appears to be Al compounds, which were shown in the Fig. 3 ( $\mathrm{f}$ ) and ( $\mathrm{g}$ ) by EDS. On the other hand, white spots were shown in the Fig. 4 (d). These are Ti and Si used as delustre particles usually imbedded in the PET filament, which are unaffected by far-infrared emission.

\subsection{Far-Infrared Emission Characteristics of ZrC-Imbedded Knitted Fabrics}

Table 5 lists the emissive power and emissivity of the heat storage knitted fabrics specimens at wavelengths between 5 and $20 \mu \mathrm{m}$. As shown in Table 5, the emissive power and emissivity of the $\mathrm{H}$ and $\mathrm{S}$ knitted fabric specimens were higher than that of the $\mathrm{C}$ specimen, which means that the $\mathrm{H}$ and $\mathrm{S}$ knitted fabric specimens have high efficiency of far-infrared emission. Figure 5 presents the emissive power and emissivity of the $\mathrm{H}$ specimens measured using an FT-IR spectrometer

\begin{tabular}{|c|c|c|}
\hline Specimens & $\begin{array}{c}\text { Emissive Power } \\
\left(\mathrm{W} / \mathrm{m}^{2}\right) \text { between } \\
5 \text { and } 20 \mu \mathrm{m}\end{array}$ & $\begin{array}{c}\text { Emissivity } \\
(-)\end{array}$ \\
\hline $\mathrm{H}$ & $3.65 \times 10^{2}$ & 0.906 \\
\hline$S$ & $3.65 \times 10^{2}$ & 0.907 \\
\hline C & $3.62 \times 10^{2}$ & 0.898 \\
\hline $\mathrm{R}$ & $3.58 \times 10^{3}$ & 0.836 \\
\hline
\end{tabular}
with an attached MCT (mercury cadmium telewriter).

Table 5. Emissive power and emissivity of the specimens.

As shown in Fig. 5(a), the maximum emissive power of the $\mathrm{ZrC}$-imbedded $\mathrm{H}$ specimen was $35.1 \mathrm{~W} / \mathrm{m} \cdot \mu \mathrm{m}$ at wavelengths between 9 and $9.5 \mu \mathrm{m}$, which was slightly higher than those of the $S$ and $C$ specimens. In addition, the sum of the emissive power of the $\mathrm{ZrC}$-imbedded $\mathrm{H}$ specimen between 5 and $20 \mu \mathrm{m}$ of wavelength was $3.65 \times 10^{2} \mathrm{~W} / \mathrm{m}^{2}$, which was larger than those of the $C$ and $R$ specimens and was attributed to the $\mathrm{ZrC}$ particles imbedded in the filament. According to Kim et al. [13], the sum of the emissive power of the germanium-imbedded PET was $3.53 \times 10^{2} \mathrm{~W} / \mathrm{m}^{2}$, which was lower than that of the $\mathrm{ZrC}$-imbedded PET. This means that the efficiency of the emissive power of the ZrC-imbedded PET was higher than that of the germanium one. On the other hand, the emissivity of the ZrC-imbedded knitted fabric specimen was 0.906 , as shown in Fig. 5(b). The emissivity 


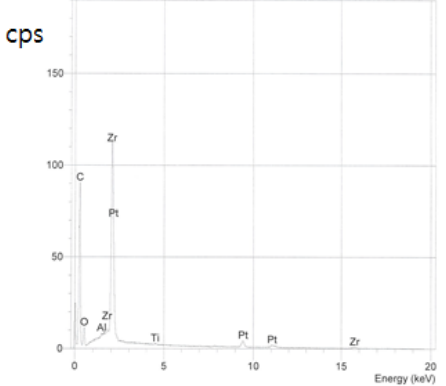

(a) $\mathrm{H}$

Peak curve

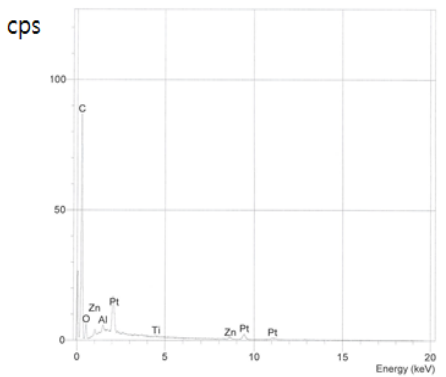

(c) C

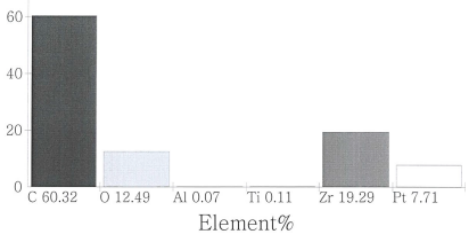

(e) $\mathrm{H}$

Content of element

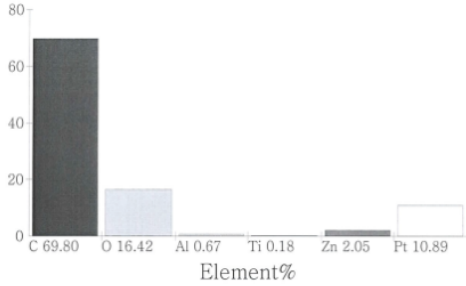

(g) C

Figure 3. Ingredient analysis of yarn specimens.

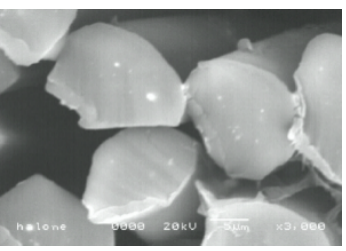

(a) $\mathrm{H}$

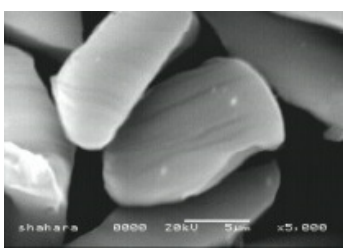

(b) $S$
Figure 4. SEM images of the yarn cross-section.

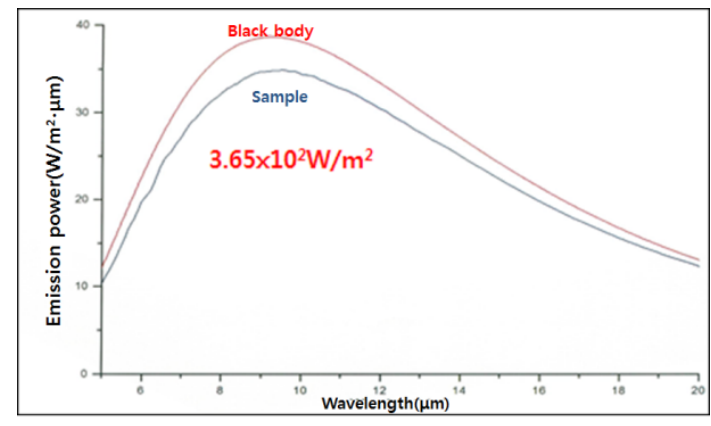

(a) Emissive power

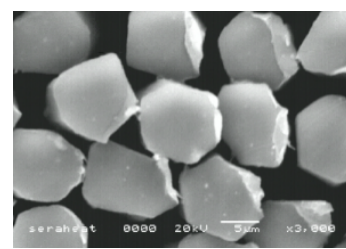

(c) C cps

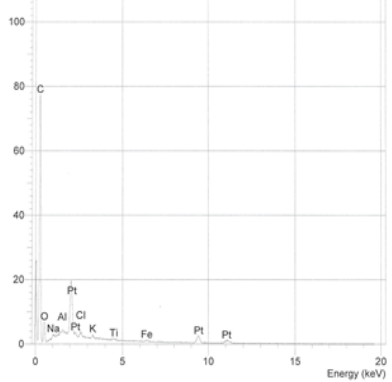

(b) $\mathrm{S}$

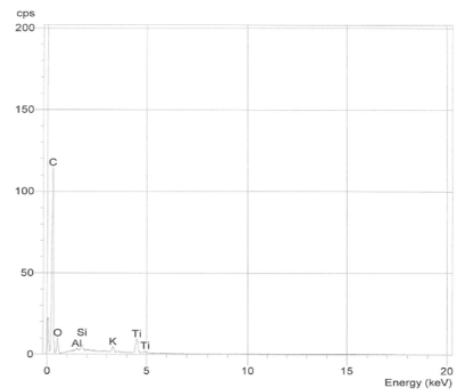

(d) $\mathrm{R}$

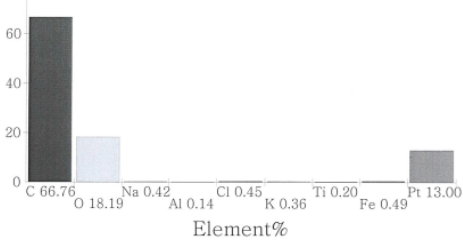

(f) $S$

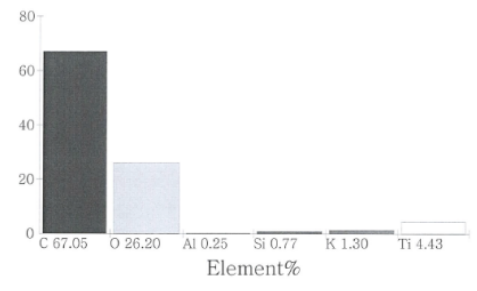

(h) R

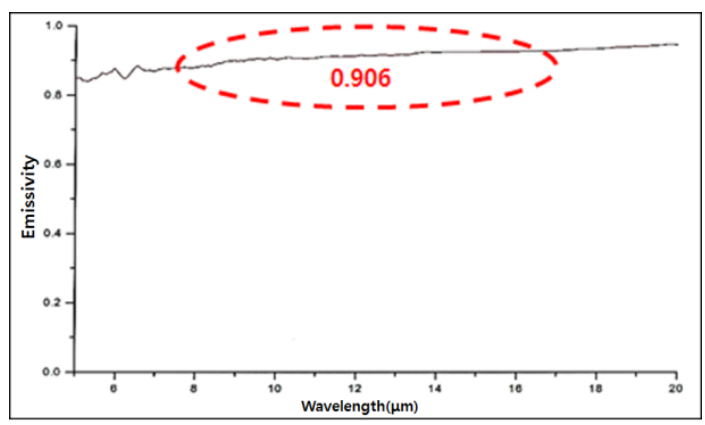

(b) Emissivity

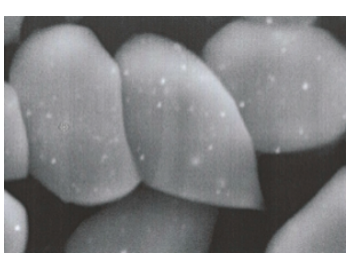

(d) R

Figure 5. Diagram of the emissive power and emissivity of $\mathrm{H}$ specimens. 
shown in Fig. 5(b) is defined as the ratio between the sum of the emissive power of the $\mathrm{Zr}$-imbedded PET and the sum of the emissive power of the black body. The average emissivity of the Zr-imbedded PET between 5 and $20 \mu \mathrm{m}$ was 0.906 , which was higher than those of the $C$ and R-PET specimens. This value was also much higher than that of the germanium-imbedded PET, which was 0.874 [13]. This means that the efficiency of the emissive power of the $\mathrm{ZrC}$-imbedded PET was better than those of regular PET and germanium-imbedded PET.

\subsection{Thermal Property of ZrC-imbedded Knitted Fabric Specimen}

Figure 6 shows the thermal property of the four kinds of knitted fabric specimens. As shown in Fig. 6(a), the maximum heat flux $\left(Q_{\text {max }}\right)$ at the transient state of the $\mathrm{ZrC}$-imbedded knitted fabric ( $\mathrm{H}$ specimen) was lower than those of the $\mathrm{S}$ and $\mathrm{C}$ specimens, and the regular PET knitted fabric ( $R$ specimen) showed the highest value in both the corduroy and crepe knitted fabrics. These phenomena were attributed to the inhibited far-infrared emitted from ZrC to flow heat and absorb near-infrared radiation, which gives it heat generating and storage properties and reduces the heat flow between the human body and knitted fabric. Similar results were reported by Shim et al. [17] and Yeo et al. [19]. Figure 6(b) and (c) show the warmth keepability and thermal conductivity in the steady state. The warmth keepability of the $\mathrm{ZrC}$-imbedded knitted fabric ( $\mathrm{H}$ specimen) was higher than that of the regular PET knitted fabric, both corduroy and crepe knitted fabrics, which can be explained similar to that of the low $Q_{\max }$ of the $Z r C$-imbedded knitted fabric (H specimen). As shown in Fig. 6(c), the thermal conductivity of the $\mathrm{ZrC}$-imbedded knitted fabric was much higher than that of the regular PET fabric, which was attributed to the high thermal conductivity of $\mathrm{ZrC}$-imbedded in the yarn.

\subsection{Moisture Absorption and Drying Properties of ZrC- imbedded Knitted Fabric Specimen}

Figure 7 shows the wicking characteristics of the four kinds of knitted fabrics measured every $10 \mathrm{~min}$ for $30 \mathrm{~min}$. As shown in Fig. 7, the wicking length of the $\mathrm{H}$ specimen was shorter than that of the S, C, and R specimens, and S specimen showed the best wicking property, which was attributed to the kidneyshaped cross section and high multifilaments of the S specimen. This means that the heat storage characteristics of the $\mathrm{ZrC}$ imbedded knitted fabric does not affect moisture absorption but wicking is influenced preferably by the cross-sectional shape and the filament numbers in the yarn, which plays an important role as the drainage of absorbed water moisture. Figure 8 presents optical microscopy and SEM images of a kidneyshaped cross section and multifilaments in the yarn of the $S$ specimen compared to the $\mathrm{H}, \mathrm{C}$, and $\mathrm{R}$ specimens.

Figure 9 shows the drying property of the four kinds of knitted fabrics with the corduroy and crepe patterns. As shown in Fig. 9, the time for the natural drying of the $\mathrm{H}$ specimen in the crepe pattern was 210 min, which was much shorter than that of the $\mathrm{S}, \mathrm{C}$, and $\mathrm{R}$ specimens. This was attributed to the fast drying of absorbed moisture in the yarn by heat particles generated from the far-infrared radiation by $\mathrm{ZrC}$ in the yarn, which showed similar results to previous research carried out by Bahng et al. [1]

\subsection{Mechanical Properties of ZrC-imbedded Knitted Fabric}

Figure 10 shows the relative mechanical properties of the four kinds of knitted fabric specimens measured using the FAST system. The extensibility, compressibility, bending, and shear rigidities of $\mathrm{ZrC}$-imbedded and ceramic-powder-imbedded knitted fabrics were plotted as the ratio values to those of the

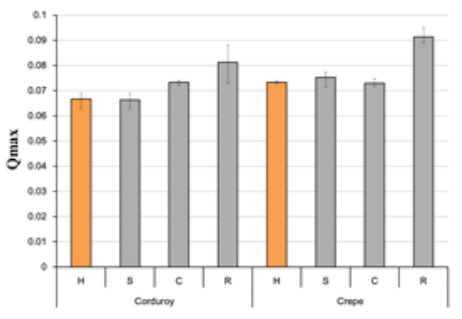

(a) $Q_{\max }$

Figure 6. Thermal property of the knitted fabric specimens.

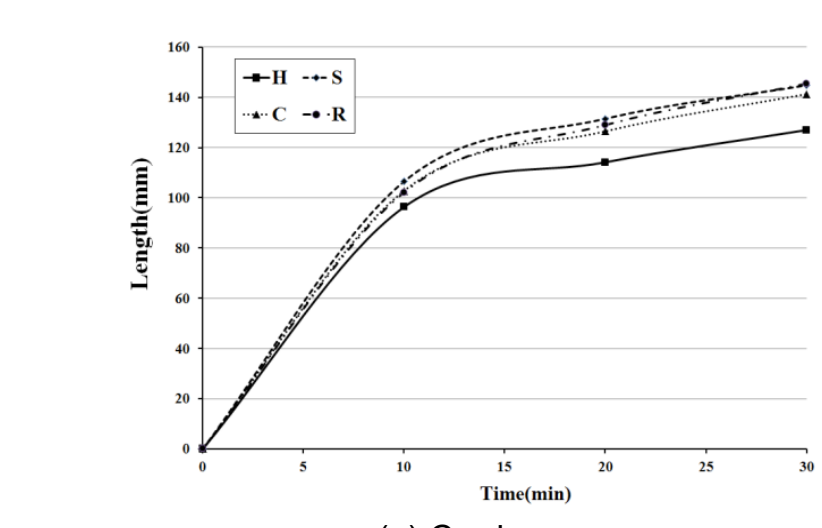

(a) Corduroy

Figure 7. Wicking property of the knitted fabric specimens.

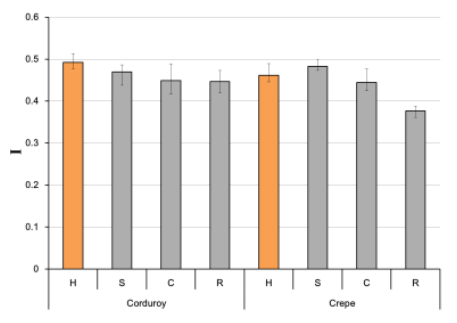

(b) I

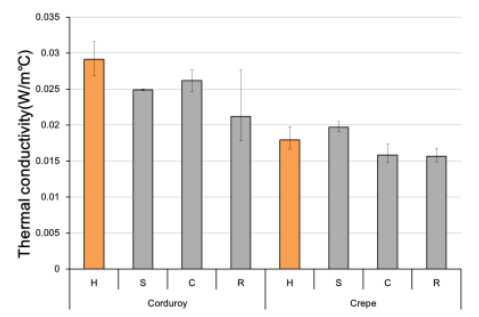

(c) $\mathrm{K}$

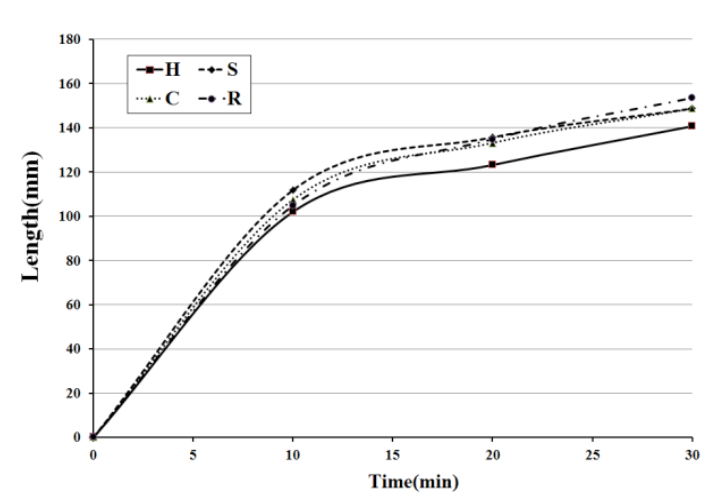

(b) Crepe 

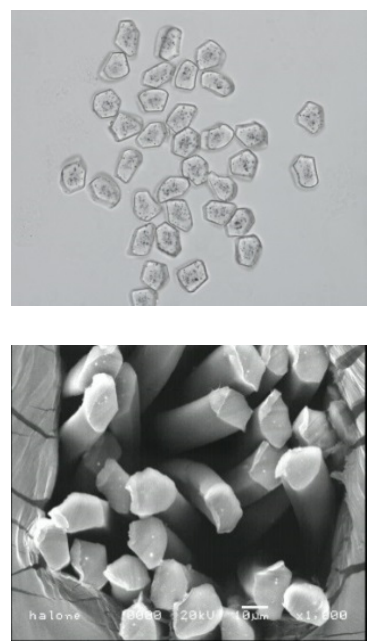

(a) $\mathrm{H}$
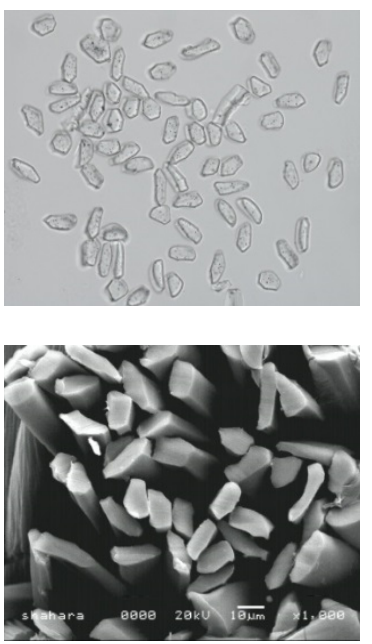

(b) $\mathrm{S}$

Figure 8. SEM images of cross sections of the yarn specimens.

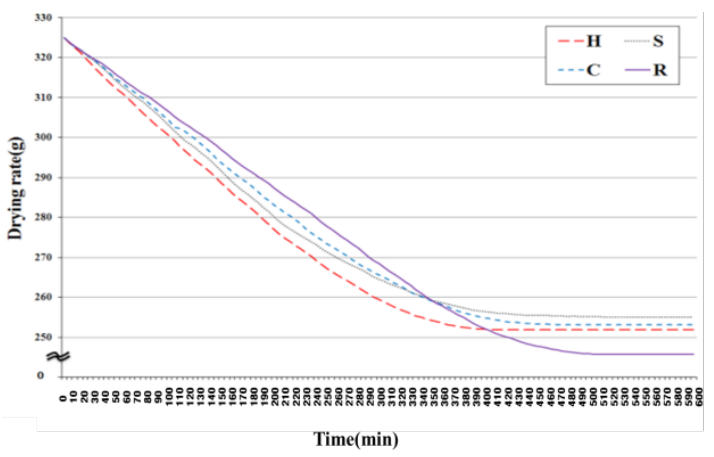

(a) Corduroy

Figure 9. Drying properties of the knitted fabric specimens.

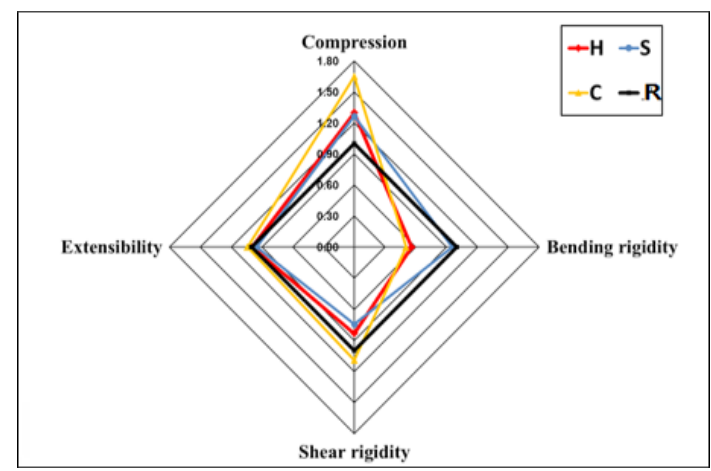

(a) Corduroy

Figure 10. Mechanical properties of the knitted fabric specimens.

regular PET knitted fabric. As shown in Fig. 10, in crepe, the compressibility of the ceramic-imbedded knitted fabrics (S, C) including $\mathrm{ZrC}$-imbedded knitted fabric $(\mathrm{H})$ were higher than that of the regular PET fabric $(R)$, which means that the ceramicimbedded knitted fabrics are more compressible than that of regular PET fabric, that is, nano-sized ceramic-imbedded particles do not affect the fabric compressibility. On the other hand, the compressibility of the ZrC-imbedded knitted fabric $(\mathrm{H})$ was lower than that of the ceramic-imbedded specimen (C), which was caused by the high $\mathrm{Zr}$ content, $19.29 \%$, of the
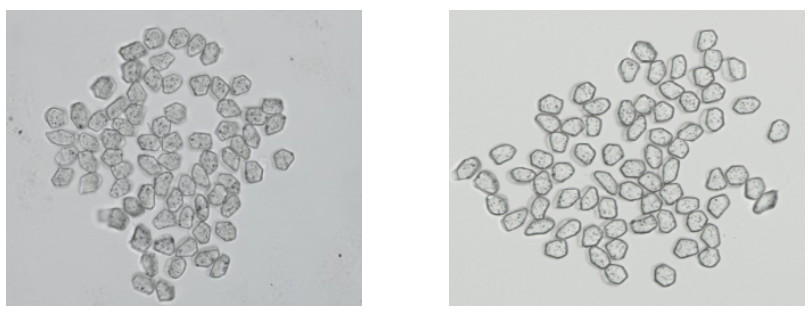

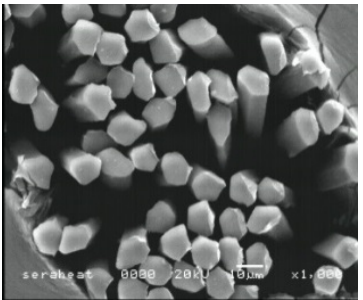

(c) C

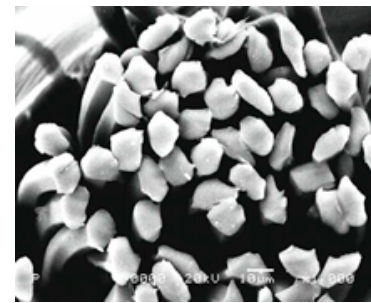

(d) $R$

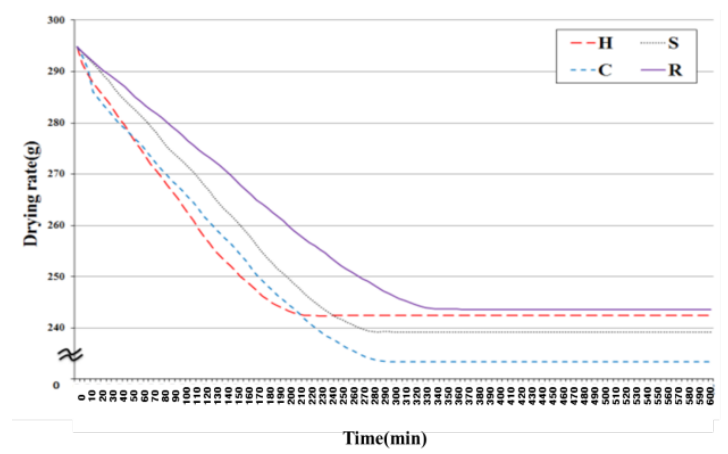

(b) Crepe

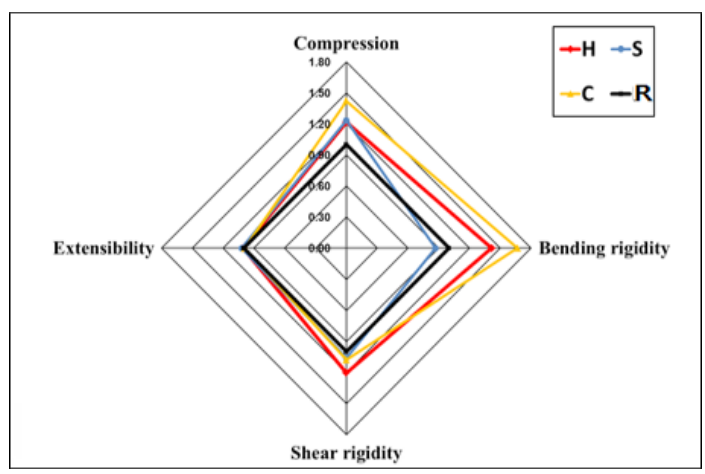

(b) Crepe
$\mathrm{H}$ specimen than that of $\mathrm{C}$ specimen, $2.05 \%$, as shown in Fig. 3. On the other hand, the bending and shear rigidities of the $\mathrm{H}$ specimen were higher than those of the regular PET fabric; however, the extensibility was similar. The ceramic and $\mathrm{ZrC}$ particles imbedded in the yarn were assumed to be protected from the in-plane deformations of bending and shear of the knitted fabric, which made high bending and shear rigidities. This means that the tactile hand of the ceramic-imbedded knitted fabrics are reasonable compared to that of the regular $\mathrm{PET}$ one. The shape retention of the ceramic-imbedded knitted 
fabrics was better than that of the regular PET fabric because of the high bending and shear rigidities. On the other hand, in corduroy, the tactile hand properties of the ceramic-imbedded knitted fabrics were contrary to those of the crepe fabric, that is, the compressibility of the $\mathrm{ZrC}$-imbedded specimen $(\mathrm{H})$ and ceramic-imbedded specimens $(\mathrm{S}, \mathrm{C})$ were higher than that of the regular PET (R), and bending rigidities of these specimens were lower than that of the regular PET, which means the shape retention of the ceramic-imbedded corduroy knitted fabric was poor, and was attributed to the distinct loop and intersecting point of the wale and course in the crepe knitted pattern, but not being obvious in corduroy, as shown in Fig. 11. Figure 11 presents two types of knitted patterns measured by SEM. This result showed that the nanoparticles imbedded in the yarns had little effect on the fabric tactile hand, which can be changed by the knitted fabric structure, such as corduroy and crepe.

\subsection{Dyeing Characteristics of the ZrC-imbedded Knitted Fabric}

The dyeing characteristics of the $\mathrm{ZrC}$-imbedded knitted fabric were compared with those of the regular PET one. Figure 12 shows the dye affinities (K/S) of four kinds of knitted fabric specimens.

As shown in Fig. 12, there were fewer changes in the dye affinity of the $\mathrm{ZrC}$-imbedded knitted fabric according to dyeing temperature and time compared to the other two ceramic imbedded and one regular PET knitted fabrics. This means that the dye affinity of the $\mathrm{ZrC}$-imbedded knitted fabric was influenced less by the dyeing temperature and time than the regular PET knitted one, which was attributed to the $\mathrm{ZrC}$ in the core of filament inhibiting the diffusion of dyestuff particles in the yarns even though the dyeing temperature and time increased. The energy saving in the dyeing process of the ZrC-imbedded knitted fabric will be possible by showing no difference in the dye affinity according to the dyeing temperature $(110,120$, and $\left.130^{\circ} \mathrm{C}\right)$ and dyeing time $(30,40$, and $60 \mathrm{~min})$, and $110^{\circ} \mathrm{C}$ and 30 min were found to be the optimal dyeing temperature and time for energy saving in the dyeing process, respectively.

\section{Conclusions}

The far-infrared emission characteristics and wear comfort property of the ZrC-imbedded heat storage knitted fabrics were examined and the following results were obtained. The amount of $\mathrm{Zr}$ imbedded in the $\mathrm{ZrC}$-imbedded yarn by ingredient analysis was $19.29 \%$. The far-infrared emissive power of the $\mathrm{ZrC}$-imbedded knitted fabric at wavelengths between 5 and 20 $\mu \mathrm{m}$ was $3.65 \times 10^{2} \mathrm{~W} / \mathrm{m}^{2}$, and the emissivity was 0.906 over the wavelength range, $5-20 \mu \mathrm{m}$, which were higher than those of the regular PET knitted fabric. The maximum heat flow $\left(Q_{\max }\right)$ of the ZrC-imbedded PET knitted fabric was lower than that of the regular PET one and the warmth keepability rate was higher than that of the regular PET one, which means that the ZrC-imbedded PET knitted fabric has heat storage properties. The wicking property of the ZrC-imbedded knitted fabric was not influenced by far-infrared emission; however, the drying property of the $\mathrm{ZrC}$-imbedded knitted fabric was much better than that of the regular PET one because of the heat emitted by far infrared from $\mathrm{ZrC}$ in the core of the filament. Summarizing the wear comfort related to the heat and water transmission, the $\mathrm{ZrC}$-imbedded knitted fabric appeared to be relevant to warm materials because of the far-infrared emitted from $\mathrm{ZrC}$, which gives it heat generating and storage properties and

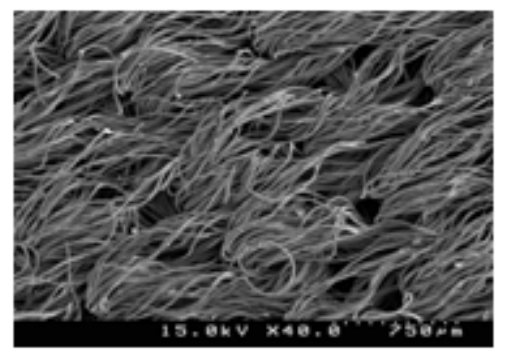

(a) Corduroy

Figure 11. Surface structure of the knitted fabrics by SEM.

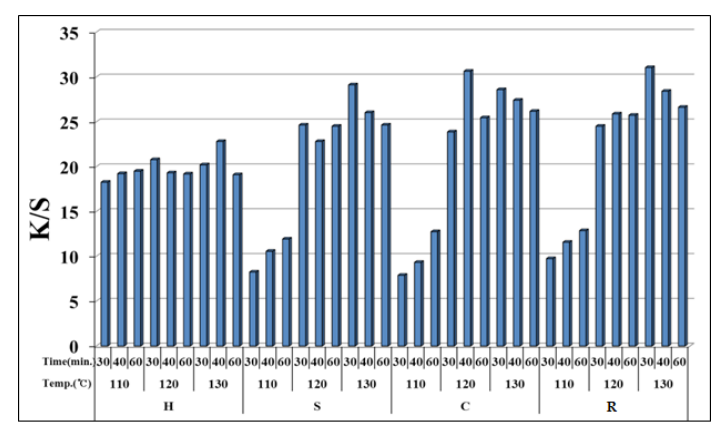

(a) Corduroy

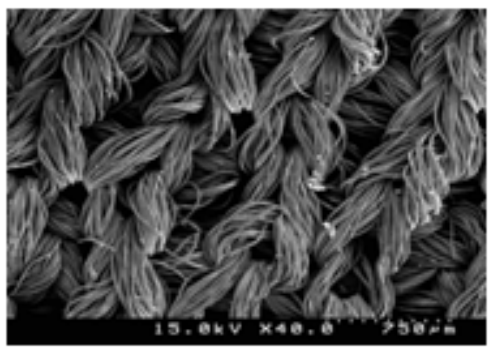

(b) Crepe

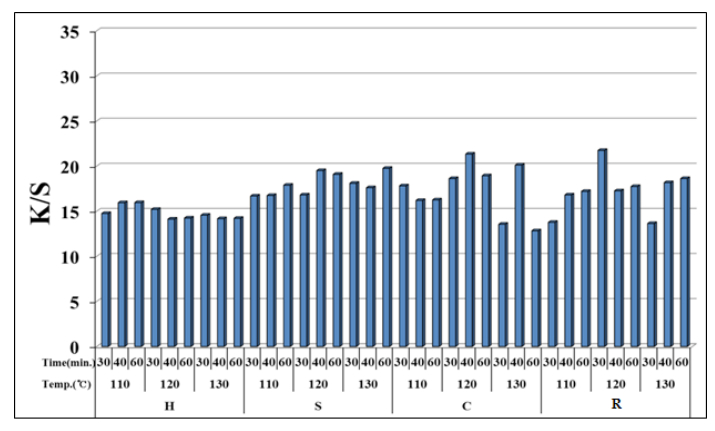

(b) Crepe

Figure 12. K/S of the knitted fabric specimens according to the dyeing condition. 
reduces heat flow between the human body and knitted fabric. In addition, the ZrC-imbedded knitted fabric had good wear comfort by fast drying of the absorbed moisture in the yarn by heat particles generated from far-infrared radiation by $\mathrm{ZrC}$ in the yarn. The tactile hand property of the $\mathrm{ZrC}$-imbedded knitted fabric was not influenced by the imbedded $\mathrm{ZrC}$ but was affected preferably by the structure of the knitted fabric. This means that the $\mathrm{ZrC}$ nanoparticles imbedded in the yarns had little effect on the mechanical properties of the fabric, which can be changed by the knitted fabric structure, such as corduroy and crepe. The dye affinity of the ZrC-imbedded PET knitted fabric was influenced less by the dyeing temperature and time than the regular $\mathrm{PET}$ knitted one, and $110^{\circ} \mathrm{C}$ and $30 \mathrm{~min}$ appeared to be the optimal dyeing temperature and dyeing time for energy saving in the dyeing process, respectively.

\section{Acknowledgement}

This research was funded by "Development of multi-functional inorganic particle embedded fibres and high comfort sports/ outdoor clothing" project.

\section{References}

[1] Bahng, G. W. \& Lee, J. D. (2014). Development of Heat-generating Polyester Fiber Harnessing Catalytic Ceramic Powder Combined with Heat-generating Super Microorganisms. Textile Research Journal, 84(11), 1220-1230.

[2] Beak, W. H. (2001). Review Optimal Hyperthermic Effect of Spectral Characteristic of Far - infrared Radiation Ceramics, Fashion \& Tex. Res. J., 3(3), 195-199.

[3] Das, A., \& Alagirusamy, R. (2010). Science in clothing comfort. Woodhead Publishing India Pvt Limited.

[4] Fan, J., \& Hunter, L. (2009). Engineering apparel fabrics and garments. The textile Institute, Woodhead Publishing Limited, Cambridge, CRC press.

[5] Furata, T., Shimizu, Y. \& Kondo, Y. (1996). Evaluating the Temperature and Humidity Characteristics of Solar Energy Absorbing and Retaining Fabric. Textile Research Journal, 66(3), 123-130
[6] Hong, S. Y., Lee, C. H. \& Kim, J. Y. (2010). Fabrication of Ceramic Particles Deposited Nano-web using Electrospinning Process and Its Far-infrared Ray Emission Property. Textile coloration and finishing, 22(2), 118-122.

[7] http://www.asahi-kasei.co.jp.

[8] http://www.kbseiren.com.

[9] http://www.kuraray.co.jp.

[10] http://www.mrc.co.jp.

[11] http://www.toray.com.

[12] http://www.unitika.co.jp.

[13] Kim, H. A. \& Kim, S. J. (2010). Far-Infrared Emission Characteristics of Germanium Included Fabrics for Emotional Garment. Korean Journal of the Science of Emotion \& Sensibility, 13(4), 687-692.

[14] Kwon, O. K. (2007). Heat delivery mechanism of textile products and development trend of keeping warmth functionalized product. Textopia, Retrieved October 20, 2014. http://www.textopia.or.kr/new/index.do

[15] Lin, C. M, \& Chang C. W. (2008). Production of thermal insulation composites containing bamboo charcoal. Text. Res. J., 78(7), 555-560.

[16] Negishi, N. \& Kikuchi, M. (1988). Infrared ray effects in biological systems. Ceramics Japan, 23(4), 335-339.

[17] Shim, M. H., Park, C. H \& Shim, H. S. (2009). Effect of Ceramics on the Physical and Thermo-Physiological Performance of Warm-up Suit. Textile Research Journal, 79(17), 1557-1564.

[18]Xin, J. H. (2006). Controlling Colourant Formulation. John H. Xin (Editor). Total Color Management in Textiles. Cambridge : Woodhead Publishing Limited, 136-159.

[19] Yeo, S. Y., Lee, D. H. \& Kim, E. A. (1998). Far IR Emission and Thermal Properties of Ceramics Coated Nylon Fabrics. J. Korean Soc. Clothing Textiles, 22(4), 515-524.

[20] Yoo, H. H., Kim, Y. H., Cho, H. T., Shim, H. J. \& Lee, K. B. (1993). Improvement of Warmth Retaining Property of Water Vapor Permeable/Waterproof Coated Nylon Fabric. J. Korean Fiber Soc, 30(3), 250-258. 